IDEAH • Vol. 2, Iss. 1 (DHSI 2019 \& 2020)

\title{
Creating a Playable History: Digital Games, Historical Skills and Learning
}

Jeffrey Lawler' ${ }^{1}$, Sean Smith ${ }^{1}$

${ }^{1}$ California University, Long Beach

Published on: Aug 19, 2021

DOI: $10.21428 / \mathrm{f} 1 \mathrm{f} 23564.22225218$

License: Creative Commons Attribution 4.0 International License (CC-BY 4.0). 
At the 2019 Digital Humanities Summer Institute (DHSI), we presented a paper that outlined the pedagogical practice that introduces historical methods to our students using video games as both primary sources that explore the history of the second half of the 20th century and and the development of digital games to present historical research. That presentation also spoke to our creation of an upper division course "Playing the Past: Games as Historical Narrative, Public Memory, and Cultural Representations” , as well as our effort to build the Center for the History of Video Games and Critical Play (criticalplay.org).

In our presentation, we suggested that historians have been slow to embrace technology as a means of bridging the gap between traditional history methods with the digital humanities, and the skills taught in many STEM programs. This paper focuses on our ongoing experiment with digital game creation in our lower and upper division history courses. A curriculum that encourages students to create history based digital games is an effective, engaging, and student-centered way to teach historical content, historiography, historical thinking skills, research methods, and other humanities-based inquiry skills. Additionally, this curriculum offers students an appealing way of thinking about historical texts while introducing them to technology and computational skills that add value to their degrees.

Our approach to the study of video games and the pedagogical uses of digital game creation in the classroom looks to craft an active learning environment that leverages historical nonfiction-based games as a tool of historical research. This project scaffolds both historical thinking tools and introduces students to a vocabulary for evaluating video games in a way that promotes an understanding of history and the historians' work. Allowing students to research, write and create games provides them an opportunity to engage in the work of the historian, test their historical interpretations, and it reinforces the importance of asking good historical research questions. An informal survey conducted in our classes at the beginning of each semester since 2018 reveals that a good number of our students' interest in history comes from the video games that they are playing or have played in their pasts. Because many of our students develop historical interests via video games, using game creation in the classroom is pedagogically feasible and appropriate. The study of video games raises critical questions about the use of history in popular media. It provides our students with creative and critical tools that challenge their a priori knowledge about the past, and to learn how and why history is written. As the final project in both our upper division course "Playing the Past" and in our United States history survey courses (part of the General Education curriculum at our 
institution), students are tasked with writing and developing their own history-based games. The use of game development to produce history allows students to approach historical production in a novel way while employing the traditional tools of historical analysis, engaging in historical narrative, and using critical thinking and research skills specific to our discipline but transferable to others.

To create their games, our students use Twine, a free and open-source tool for creating narrative-based interactive games. Twine requires little to no previous coding experience but, as the developers tell us, "you can extend your stories with variables, conditional logic, images, CSS, and JavaScript" (Twine, Twinery.org). Twine games are reminiscent of the Choose Your Own Adventure books popular in North America during the 1980s. In Twine, authors work in a web browser or a local instance of the program to craft passages in a simple text-based editor. Each passage is linked to another using text enclosed in double brackets. Any text wrapped in those brackets creates one or more links and a choice for the player to follow. Over the past several years, Twine has found success in non-traditional gaming spaces. In fact, it gained popularity in the queer gaming community by giving them a voice in gaming circles. The first popular video games to leverage Twine were "Depression Quest" and "Queers in Love at the End of the World," both of which tackled sensitive issues and were controversial when they were released. Since then, Twine has become a popular tool in creative writing and other humanities classrooms including in history.

It should be said that the use of Twine in the classroom in general and in the history classroom, in particular, is not new (see for instance, Jeremiah McCall, Gaming the Past), nor should it be used only to engage students in some playful new form (see for instance, Brandee Easter, Teaching with Twine). Twine can immerse students directly in the historical process and allow them to discern causation, discover the role and importance of agency and choice, engage in interpretive historical narrative creation, and learn to analyze, connect, and apply primary sources to said narrative. Our experience and the research of others, suggest these skills can be difficult for students to integrate or recognize in traditional assignments as they often look at the past through a progressive teleological lens. This assignment challenges their epistemological knowledge that is often rooted in early public education and heritage-based teaching models (Samuel Wineburg, Why 83; Robert B. Bain 334).

While historians have spent the latter quarter of the $20^{\text {th }}$ and the first part of the early $21^{\text {st }}$ century challenging traditional narratives and addressing marginalized subjects, the $\mathrm{K}-12$ classroom is still rooted in heritage-based textbooks and narrative production 
(Wineburg, Historical 257). We find every semester that students are stupefied that they "have been lied to" for so long or that there are so many other stories that they could have examined and connected to their lives. Writing history through video games allows our students to construct stories that speak to their place in the world. The personal becomes historical and authenticates our students' world view, legitimizes their place in history, helps them to align their ideals with a larger historical conscientiousness, and deepens their historical empathy and engagement with the past. Many students reflected sentiments similar to this student response from a modern U.S. survey course where game creation was implemented as a semester long project, "By looking to the past, we can understand how these marginalized and oppressed groups overcame their obstacles which will help those who are struggling against oppression today" (Student Reflection, History 172 California State University, Long Beach. Spring 2019). Yet, getting students to the point where they can internalize the complexities of knowing the past takes time and organization. This generally occurs during weeks nine through sixteen of our sixteenweek semester and is intermixed with traditional content. We follow the same model regardless of student level or major. Before delving into the full project, students are introduced to the basic structure of Twine and build short, rudimentary practice games about a historical subject of their choosing. The practice games allow students to familiarize themselves with the technical aspects of Twine and its interactive capabilities.

Having developed basic technical competence with Twine, we transition their learning to historical content and essential historical understanding and have them submit an introductory proposal that outlines the subject of their game. The class begins their major course assignment. Phase one is research. At this point students begin to see the depth and difficulty of crafting a historical narrative-based game as they come to terms with research tools and databases, learning how to read secondary and primary sources, and implementing proper citation methods. In phase two, students formalizethe purpose of their game, develop their player and non-player characters (NPCs) and begin to craft the historical world they will occupy. The creation of historically plausible characters requires a solid understanding of their chosen era' $s$ historical context. The final phase, game development, takes place in the last two to four weeks of the semester, where students assemble their their prepatory work into a game that is a convincing and historicallysituated. To reinforce the need to historicize the game, the assignment also asks them to define the historical purpose of their game. This purpose becomes the argument or thesis for the game, helps guide their narrative, and reinforces the notion of interpretive history. 
Like any class that introduces students to historical research, our classes initially need to come to terms with a basic understanding of what history is and how historians collect evidence and write about the past. Historians have long debated the nature and meaning of history. How is it made? How is it different from a simple regurgitation of historical facts? (Bruce VanSledright 26-27; Wineburg, Historical 17; Peter J. Lee 31-33; Ross Dunn 122-125). Explaining this complicated disciplinary argument to students is difficult. It is especially challenging to explain the nuances of historical discourse to first year students. The first few weeks of all our courses are dedicated to the discussion of modern research methods. Our goal is to teach students that history is an attempt to reconstruct the past using discipline-specific methods and that, because history creates meaning from evidentiary fragments left behind, it is as reliant on the historian as it is on the evidence (Ginzberg 1-2).

To make an effective historical Twine game, students must engage in traditional methods of interpretive evaluation. They must learn to make critical choices about sources they select, the argument their game makes, and the narrative they construct to illustrate this argument. Once their proposals have been accepted, students begin their primary and secondary source research. For our first-year students this is often their first foray into academic research, so we limit the number of primary sources to ten, secondary sources are limited to 3, and we ask that they reference their textbook and in class lecture and discussion material in their work. Our lower division students are also offered a list of suitable primary and secondary source repositories both online and from our library (although the COVID-19 pandemic forced us to work entirely online during this last year) from which they can draw their source material. Our upper division students, all of whom have had to take a previous methods class upon declaring as a history major, are given more freedom and independence in their research. Those upper division students are also asked to draw from recent peer reviewed journal articles and interlibrary loans. If students reference popular they must submit a justification in their annotated bibliographies. Our upper division students are also asked to keep a research journal. This diary helps them see how their thinking evolves and to make connections between their sources. The result for both upper division and lower division students is an initial bibliography that is later refined and annotated suggesting how each source will be used in the project and what each source says about the past they are creating.

While the research done in these games centered courses parallel the research our students would produce in any research project, be it a midterm essay or a formal paper, students in the games-based courses report being more deeply engaged in a wider variety of primary and secondary sources. As one of our upper division students noted, "I can 
honestly say that I did more research for my game than I have ever done for any paper, and it was [a continual] part of the process until the very end. I noticed myself searching for information that would let me create options that I wanted available for players." They also connected their work to traditional scholarship. One said, "I think that [our research] can be compared to how historians will sift through information and search for the pieces that tell the stories they want to tell." Regardless of their level of expertise, doing this type of structured research led many of our students to question what historical moments, ideas, or events were important to include when building a historical argument and the importance of the causal relationship between events and sources. The freedom to choose and write their own characters, and to research and evaluate their source material allowed students to follow their personal interests and resulted in work that offered a more inclusive set of interpretations. As one student suggested about this experience, "The best lesson the Twine game has taught me was[...] how important it is to perform research when learning about a topic you think you know all about. I found myself losing sleep seeking primary sources to make my work as accurate as it could be.”

'Twine further deepens students' understanding of the historical process by engaging them directly in manufacturing possible historical choices that are based on reliable and historical primary and secondary sources.. Twine necessitates the creation of choices and forces students to examine the possibilities historical actors facedAs Dawn Spring writes,

"In developing the scholarly game, historical thinking and historical research methodologies can inform the design process" (Spring 218). Our assignments have students incorporate appropriate historical context into their characters. Synthesizing their research facilitates an understanding of larger historical questions and difficulties of knowing the past. "You have to [provide] your "audience" [with] empathy and a really vivid description so they feel for the character and more importantly so they can imagine the whole scenario ...What were his feelings, why did he do what he did?" (Student Reflection, History 173 California State University, Long Beach. Fall 2019) During game development, students make concrete choices about their subjects, their characters, and the direction of the narrative based on their own research and analysis of documents.

Game development and the player character development process provide an additional area of student agency in their work and made the narrative contingent on their own research and interpretations. An early assignment in the game development project asks students to write a short character sketch of their main character and one or two NPCs who will have a role in the game' s main narrative. Students position the characters in society, describe embedded historical character traits, and discuss how their characters 
will navigate the historical setting of the game. The assignment then asks them to consider the historical agency and choices that will be demonstrated through their characters. The novelty of character creation connects students to the historical era they are researching. We are able to judge the efficacy of these methods through postassignment reflections. One student said, "[I felt] a deeper connection with the history I researched with the hopes of immersing an audience into the $15^{\text {th }}$ century age of exploration." Another explained, "[the game I created] made me think more critically with history [sic] and made me understand my research in a completely different way." Others expressed pride in work that was unusual and many reported that they wanted to continue to work on the games after their final project was over. This demonstrates a connection between the production of history in this new form and student engagement.

Given the freedom to create characters for their games, students began to envision history from a perspective different from traditional history texts, texts which often leave out or marginalize the stories. The following student response was indicative of the variety of subjects students investigated and the association many students made with the present, "Studying 1920s U.S. history and women's fight for equality helped me understand that humans will always fight back when they are being oppressed... Today, people of color are fighting racism, immigrants are fighting back against xenophobia, and women are still fighting sexism." History that is personalized helps attach students to the past and provides them with a creative opportunity to tell a story that fits within their own lived experiences or interests and expands the ability of the history curriculum to teach about the past through the lens of the student (Roy Rosenzweig and David Thelen 16-18). Character creation encourages students to think about what is most important to focus on in their game and to ask how their character will navigate the historical space. In-game choices also demonstrate the intricate and varied ways that historical agents engaged with -and were controlled by-internal and external forces.

The value of having students create a historically plausible character removes issues surrounding the use of real historical figures whose choices are cemented in their own pasts. The video game model requires students to think about what stories to tell and from what vantage to tell those stories. Interestingly, in our survey courses, many of the projects have focused on the historical experience of marginalized groups, including Native Americans, the enslaved or freed people, women, and the working class. Choosing to highlight these voices led students to question what moments, ideas, or events were important to include when telling the history of the United States thus revealing a more inclusive history that better met our students' needs and placed their own experience into the story of the past. This agency also helped demonstrate to our students the 
relationship between historical narrative and source selection that historians use to tell the story of the past.

For students, game creation allows them to engage in the work of the historian, synthesizing their research, analyzing documents, and crafting a historical argument. Once students learn how to use Twine, formalize their historical topic, research the subject matter, and create historically rooted characters, they begin game development. Even though students' research and ideas have coalesced at this point, game development and creation highlight the difficulty in writing a historically accurate story based on how they read and connect evidence. It is often the moment when students realize the difference between what they are used to reading and memorizing from textbooks and how historians attempt to tell accurate stories about the past (VanSledright 36-37). As one portion of our assignment states, "the decision tree for the game needs to focus on the variety of choices and consequences... and how different choices might lead to different historically plausible endings." Students were forced to confront their general teleological understanding of the past. At this point, students needed to make critical decisions about what portions of their research were relevant and necessary to the telling of their story, just as historians and other humanity-based disciplines must edit and curate their own work (Edward Hallet Carr 1-10). Choosing and connecting evidence into a historical narrative that plots a character's choices within that environment challenged students to closely examine their sources.

The assignment' $s$ main objective was for students to design a game demonstrating their personalized understanding of the past. In their 1998 study, Rosenzweig and Thelen investigated how Americans connect to the past. They argued that individuals prefer a history closer to their own experiences and one that is derived from their discovery and making. The least favorite method of doing or learning history according to respondents in the study was "studying history in school" (Rosenzweig and Thelen 31). This sentiment obviously presents a challenge to history professors which is why moving historical creation and the narrative process to our students has the potential to reify students' connection to the past and its meaning. Using game creation in the classroom provides students the opportunity to engage with the past on their terms while maintaining strong methodological underpinnings rooted in research, analysis, and contextual contingency. Student response to learning and engaging with history was positive overall with several students echoing responses such as, "I was more engaged to learn about history, through creating this game with my group, than I would' ve by solely reading from a textbook and taking exams." 
While students often feel engaged in the creation of their historical game, coherent and precise instruction on the mechanics of Twine and its capabilities are necessary. Finding a balance between the technical side of the game and the development of historical content can be delicate. Students come to our classes with limited computer skills and some are frustrated that they are required to learn a new piece of software in a history class. To be fair, this method does put an added onus on our students. Not only are they engaged in the difficult activity of historical study, but are also facing the added issues of writing in a non-traditional format. In our upper division history specific courses, some students simply want to return to traditional paper writing or other familiar assessment tools. In our survey courses, some students suggested game creation was difficult to align with their prior conception of history. While we see the pedagogical value that game creation affords, we recognize that students may struggle with this non-traditional approach.

Twine is a powerful game engine that with sufficient proficiency can produce sophisticated narrative games but most of our students do not have the time or prior skill necessary to gain this proficiency. In its simplest form, Twine presents an if/then platform that can reinforce students' already binary historical thinking, and without proper instruction, their games can become uncomplicated A/B paths that offer limited player choice and exemplify an assumed historical causality and teleological approach to the past. Student games that employ this structure even when well researched and written feel constrained and offer little of the variability of actual historical moments. But even these simple games demonstrate their pedagogical value because students gain research and critical reading skills, while learning how to connect evidence into their narrative. Most issues created by simple choice trees are easily remedied by adding randomness and probability. Coding in Twine is within the technical reach of most, but it is time consuming and can take away from content coverage. For some of our students, the challenge and novelty of coding rather than traditional historical writing are exciting and can become an all-encompassing part of their project. The students who focus on the technical side of game development craft digital games that are sophisticated from a mechanics point of view (probability, randomness, inventory systems, the use of dice rolls, and so on), but often lack the historical content and interpretive depth that is a primary goal of the assignment. Balancing the content and technical aspects of Twine requires instructor vigilance. It is necessary to consistently check in on students' games. Several low-stakes steps throughout the semester help to maintain consistent use of both historical and technical skills. Additionally, this curriculum reinforces the collaborative 
nature of digital scholarship and the value of a shared community in an active learning environment.

Twine' s lack of real-time collaboration is frustrating to students familiar with other collaborative tools like Google Docs. Twine' s workaround, perceived by students as complicated, recommends that you "export your story to a file using either the Publish to File option in the story menu (to export a single story) or the Archive button on the story list (for a set of stories) [and ] then give your collaborators this file to import in turn" (The Twine Cookbook, https://winery.org/cookbook). These limitations can be remedied by limiting the number of students in a group and letting the group assign specific roles of project manager, researcher, coder, and content creator/media finder. In this way the assignment models real world scenarios in cross-disciplinary digital humanities collaborations.

Overall, the experience of creating digital games was interactive, participatory, and immersive. Students reported that creating a digital game offered them a deeper interest in history in general, more agency, and a better historical understanding of their chosen topics. And while the experience and outcomes from each class have differed in relation to time, major, and class level, the use of simple game development in the university classroom has clear benefits. When students apply historical methods, they become more actively engaged in discovering relationships and making connections. At the same time, using game creation in the classroom results in an increased historical understanding, better retention of information, and a deeper understanding of the historical process. Matthew Wilhelm Kapell and Andrew B. R. Elliot argue that developing and playing historical video games "allows for an in-depth understanding not just of facts, dates, and people or events, but also of the complex discourse of contingency, conditions, and circumstances, which underpins a genuine understanding of history" (Kapell and Elliot 408-409). We applied this premise to a constructivist pedagogical model when we brought our students together to create personal and contingent history. Through gameplay, students immerse themselves and their players (often their peers in class) in a deeper understanding of history and the historical process. As Spring suggests, the historian (in this case the student) "must determine how they want the player to experience the historical moment" (Spring 216). For students, the game creation model presents them with the opportunity to think about what stories are important to tell and what vantage point to take when drawing them out of more traditional forms of research and analysis. Ultimately, our aim in using game engines is to have students explore historical authorship in a new way. Twine allows them an opportunity to gain an understanding of 
the context, contingency, and choice that faced all historical actors in the past and that is why it is an effective way to teach history.

\section{Works Cited}

Bain, Robert B. "Into the Breach: Using Research and Theory to Shape History Instruction." Journal of Education, vol. 189, no. 1/ 2, 2008, pp. 159-167. JSTOR, www.jstor.org/stable/42748666.

Carr, Edward Hallett. What Is History? St. Martin's Press, 1961.

Chapman, Adam. 'It' s Hard to Play in the Trenches: World War I, Collective Memory and Videogames.' Game Studies, vol. 16, no. 2. Dec. 2016.

gamestudies.org/1602/articles/chapman. Accessed 12 September 2020.

- _ Digital Games as History: How Videogames Represent the Past and Offer Access to Historical Practice. Routledge, 2016.

Dunn, Ross. "Constructing World History in the Classroom." Knowing, Teaching and Learning History, edited by Peter Stearns, New York University Press, 2000, pp. 121-140.

Easter, Brandee. Teaching with Twine, March 19 ${ }^{\text {th }}, 2015$, teachingwithtwine.wordpress.com/resources/. Accessed 12 September 2020.

Ginzburg, Carlo et al. Threads and Traces: True False Fictive. University of California Press, 2012.

Goss, Mary. "Tension and Fear." The CUNY Games Network, edited by Carolyn Stallard, 2018, games.commons.gc.cuny.edu/2018/10/29/guest-blogger-mary-gross-tension-andfearl. Accessed 1 September 2020.

Kapell, Matthew Wilhelm and Andrew B. R. Elliot, editors. Playing with the Past: Digital Games and Simulation of History. Bloomsbury Publishing - Academic Division, 2013. ResearchGate, doi.org/10.5040/9781628928259.

Lee, Peter J. "Putting Principals into Practice: Understanding History." How Students Learn: History in the Classroom, edited by Suzann Donovan and John D. Bransford, National Academies Press, 2005, pp. 31-51. 
McCall, Jeremiah. Gaming the Past: Using Video Games to Teach Secondary History. Routledge, 2011. ResearchGate, doi.org/10.4324/9780203831830.

Roberts, Scott L. “Using Counterfactual History to Enhance Students' Historical Understanding." The Social Studies, vol. 102, no. 3, May 2011, pp. 117-123, ResearchGate, doi.org/10.1080/00377996.2010.525547.

Rosenzweig, Roy and David Thelen. The Presence of the Past: Popular Uses of History in American Life. Columbia University Press, 1998.

Spring, Dawn. "Gaming History: Computer and Video Games as Historical

Scholarship.” Rethinking History, vol. 19, no. 2, 2014, pp. 207-221.

Uricchio, William. "Simulation, History, and Computer Games." Handbook of Computer Games Studies, edited by Joost Raessens and Jeffrey Goldstein, 2005 pp. 327338.

VanSledright, Bruce. In Search of America's Past: Learning to Read History in Elementary School. Teachers College Press, 2002.

Wineburg, Samuel. Why Learn History (When it's Already on Your Phone). University of Chicago Press, 2018.

- - Historical Thinking and Other Unnatural Acts: Charting the Future of Teaching the Past. Temple University Press, 2001. 